\title{
СИМВОЛИЧЕСКИЕ ПРИЗНАКИ КОНЦЕПТА «СОЛНЦЕ» В КИТАЙСКОЙ ЯЗЫКОВОЙ КАРТИНЕ МИРА
}

\section{SYMBOLIC SIGNS OF THE "SUN" CONCEPT IN THE CHINESE LANGUAGE PICTURE OF THE WORLD}

Ma Jiaqi

Summary: In this article, the author examines the features of the objectification of symbolic features of the concept of «sun» in the Chinese linguistic picture of the world. To achieve this goal, the methods of conceptual linguoculturological analysis are used. Linguistic symbols are of an archetypal nature. They combine different planes of reality into a single whole in the process of semantic activity in a particular culture. The symbol has a rich range of reproducibility in both oral and written speech and virtually endless boundaries of semantic interpretation. The prospect of seeing a symbol in a context turns into a breadth of semantic variation. On the basis of a large phraseological dictionary of the Chinese language, as well as these dictionaries of symbols, conceptual metaphors are analyzed that verbalize symbolic signs characteristic of the Chinese conceptual system: «truth», «fact», «emperor».

Keywords: sun, linguistic picture of the world, concept, linguoculture, symbolic signs of the concept.

\author{
Ма Цзяци \\ Московский государственный университет, г. Москва \\ 1119623392@qq.com
}

Аннотация: В данной статье автор рассматривает особенности объективации символических признаков концепта «солнце» в китайской языковой картине мира. Для достижения поставленной цели используются методы концептуального лингвокультурологического анализа. Языковые символы имеют архетипическую природу. Они объединяют разные планы реальности в единое целое в процессе семантической деятельности в той или иной культуре. У символа богатый спектр воспроизводимости как в устной, так и в письменной речи и фактически нескончаемые границы смысловой интерпретации. Перспективность видения символа в контексте оборачивается широтой смыслового варьирования. На основе большого фразеологического словари китайского языка, а также данных словарей символов анализируются концептуальные метафоры, вербализирующие характерные для китайской концептуальной системы символические признаки: «правда», «факт», «император»

Ключевые слова: солнце, языковая картина мира, концепт, лингвокультура, символические признаки концепта.

\section{Введение:}

$\mathrm{B}$ о многих китайских фразеологизмах «солнце» обретает поэтическую окраску и обрастают множеством значений. Они давно стали символами искусства. Солнце (太阳，日) в китайской литературе - образ прекрасного и романтичного [2].

Фразеологизмы являются важной частью китайского словаря и являются метафорическими. Фразеологизмы с концептом «солнце» - это метафорический механизм исходной области для солнца. В китайской фразеологии также обнаруживается достаточно большое количество фразеологизмов, пословиц и поговорок, посвященных небесным светилам [1]. Нами были проанализированы данные фразеологических словарей, на основании которых мы подобрали фразеологизмы китайского языка с компонентами «солнце».

Солнце - один из древнейших символов, встречающихся во многих религиях и культурах. С древних времен люди смотрели на небо и пытались объяснить миф об этом явлении. Мифопоэтические представления народа о небе и небесных объектах представляют интерес для когнитологов, описывающих концептуальные струк- туры с позиций символических признаков. Методика описания этих признаков в данной статье основывается на концептуальном анализе репрезентантов анализируемого концепта и на этимологическом анализе слова, вербализующего концепт солнца.

\section{1. Положение/ солнше}

Солнце -это небесные тела во Вселенной, действие каждого небесного тела имеет свои законы, именно поэтому древние испытывали сильное любопытство к небесным светилам. Поскольку Земля движется с запада на восток, все небесные тела совершают круговое движение, поэтому солнце и луна поднимаются и опускаются ежедневно, а звезды также имеют разные скорости и циклы движения. Для небесных светил существует множество фразеологизмов, описывающих изменения положения небесного тела как исходной области. О солнце в основном говорится, что оно утреннее, в зените и закатывающееся, это проецируется на статус человека в обществе. Например, «詚日东升》 (взошедшее солнце поднимается на востоке), «如日方中» (как солнце в зените), «日薄西山» (солнце садится за западные холмы) [3]. Метафорические приемы используются, чтобы соответственно показать положение солнца с разными пере- 
носными значениями, такими как начало, расцвет и упадок. «暗无天日» (беспросветная тьма) имеет переносное значение - наступили тёмные времена, люди находятся в сложной ситуации, существует опасность. В фразеологизме используется метафорический приём описания темноты для отражения опасности, негативных настроений в обществе.

\section{2. Появление и исчезновение/солнше}

Свет представляет надежду, жизнь, святость и другие прекрасные характеристики. Солнце - это естественные светящиеся небесные тела, поэтому они имеют прекрасные переносные значения. Свет противопоставлен тьме, свет небесных светил иногда исчезает. Солнце может быть затемнен серыми облаками, что указывает на то, что соотношение между добром и злом. Но темные времена продлятся недолго, потому что темные тучи в конце концов уйдут, солнце снова засияет. Люди описывают добрые мечты и оптимистичное настроение с помощью солнца. Например, «拨云见日» (рассеялись облака, и показалось солнце). Метафорические приемы используются, чтобы выразить преодоление трудностей и торжество добра.

\section{3. Способность, талант человека/солнше}

Солнце не подвластен ничьей воле. При описании доминирования над «солнцем», обычно подразумевается, что человек превосходит эти силы, он выступает талантливым мастером своего дела. Например, «挥戈 反日» (размахивать копьём против солнца). Этот прием используется, чтобы описать преодоление трудностей и достижение цели. Во фразеологизме используются неподвластные человеку возможности как исходную область и проецируют ее на целевую область таланта и способность человека, с целью описать того, кто обладает талантом.

\section{4. Время/солнше}

Восход и закат солнца представляет собой ход времени. Древние люди привыкли определять время, наблюдая за положением солнца на небе. Например, «日
不移影》 (в тот же момент, не теряя ни минуты). Его переносное значение - описание очень короткого времени. Такой метафорический прием как недалекое передвижение солнца используется, чтобы описать очень короткое время.

\section{5. Миф/солнше}

Часть фразеологизмов с компонентом «небесные светила» основана на аллюзиях всей легенды в качестве исходной области. При использовании этих фразеологизмов нужно думать об переносных значениях, а не только полагаться на прямые значения. Например, «夸父 逐日» (Куа-фу гнался за солнцем).

\section{6. Теплота и яркость/солнше}

Как показывает материал, температурными характеристиками исходной области обладает в основном «солнце». Там, где есть солнечный свет, температура будет относительно высокой, а там, где лунный свет энергия звездного света слабая, люди не могут почувствовать повышения температуры. Солнце в разные периоды времени дарит людям разные ощущения: летнее солнце сильное и жаркое, оно невыносимо, например:“ 风吹日晒》(ветер продувает и солнце опаляет), 《日多风管》 (Светит солнце, дует ветер)，《严霜烈曰»(палящее солнце), «骄阳似火»(солнце, обжигающее как огонь). В этих словах «晒》 (греет солнечными лучами), «受》 (обжигать, 《烈»(пылающий), «火»«пылающий огонь» отражается высокая температура и интенсивность солнца летом. В фразеологизмах 《风和日暖》(приятный ветер и теплое солнце), «阳煦山立»( теплое солнце), «暖»(тепло), « 煦»(тёплое и ласковое солнце) отражается теплота солнца, которое приносит людям приятные ощущения.

\section{Зак^ючение}

Проведенный анализ показал, что концепт «солнце» отражает донаучные, мифологические представления народа о мире, обладает ценностными характеристиками и множеством различных образных фольклорносимволических признаков, значимыми для носителей китайской лингвокультуры.

\section{ЛИТЕРАТУРА}

1. Большой фразеологический словарь китайского языка, 2013, с. 65

2.《成语大词典》编委会.成语大词典(彩色本)[M]. 北京:商务印书馆, 2013.1433c.

3. 岑玉珍.发展汉语·高级汉语[M].北京: 北京语言大学出版社,2005. 196c.

(с) Ма Цзяци (1119623392@qq.com).

Журнал «Современная наука: актуальные проблемы теории и практики» 